\title{
QUALIDADE FÍSICA E FISIOLÓGICA DE SEMENTES DE TRIGO EXPURGADAS COM FOSFINA DURANTE OARMAZENAMENTO ${ }^{1}$
}

\author{
LAÉRCIOSOARESROCHAJÚNIOR ${ }^{2}$, ROBERTOUSBERT ${ }^{3}$
}

\begin{abstract}
RESUMO - Foram avaliados os efeitos físicos e fisiológicos em sementes de trigo, da aplicação trimestral de 1, 2, 4 e $8 \mathrm{~g} \cdot \mathrm{m}^{-3}$ de fosfina $\left(\mathrm{PH}_{3}\right)$, em exposição de 120 horas, durante um período de doze meses de armazenamento. Foram utilizadas sementes das cultivares IAC-24 e IAC-362, produzidas na safra de 2000 no Centro Experimental do Instituto Agronômico de Campinas. Após a colheita, secagem e beneficiamento, as sementes foram armazenadas em condições de ambiente não controlado e trimestralmente foram avaliados o grau de umidade, as sementes infestadas, $o$ peso hectolítrico, a germinação e o vigor (envelhecimento acelerado). Não foram observadas interações significativas entre dosagens de fosfina e cultivares de trigo durante todo o experimento. Verificou-se que, no decorrer do armazenamento, houve aumento no grau de umidade e na infestação de sementes e redução do peso hectolítrico no tratamento controle, devido ao intenso ataque de pragas, principalmente Sitophilus spp., que mostraram maior preferência pelas sementes da cultivar IAC-362; por outro lado, as aplicações de fosfina nas diferentes dosagens foram eficientes, resultando em níveis de infestação das sementes inferiores a 1\%, após 12 meses de armazenamento. Os intervalos de aplicação trimestral da fosfina foram eficazes no controle da praga. A germinação e o vigor tiveram reduções crescentes no tratamento controle durante o período avaliado.
\end{abstract}

Termos para indexação: Triticum aestivum, fumigação, germinação, vigor.

\section{PHYSICALAND PHYSIOLOGICALQUALITY OF OPEN-STORED WHEAT SEEDS AFTER PHOSPHINE APPLICATION}

\begin{abstract}
Physical and physiological effects due to $1,2,4$ and $8 \mathrm{~g} / \mathrm{m}^{3}$ of phosphine, applied during 120 hours at 3-month intervals, during 12-month-open-storage of wheat seeds were analysed. The cultivars used were IAC-24 and IAC-362, harvest at 2000 season in Campinas Agronomic Institute fields. After harvesting, drying and processing operations, seeds were kept in open storage conditions and percentages of moisture content, infested seeds, hectolitre volumetric weight, germination and vigour (accelerated ageing) values were recorded at 3-month intervals. No statistical interactions were detected among phosphine doses and wheat cultivars throughout the experiment. Control treatment showed increases on seed infestation and moisture content values, while hectolitre weight was reduced, due to an intense plague attack (Sitophilus spp.), mainly in cultivar IAC-362 seeds. Phosphine applications were effective as to controlling it, showing incidence levels below 1\%, after 12-month storage period; however 3-month-interval phosphine application had no effect on larva control. Germination and vigour (accelerated ageing) percentages presented reductions in control treatment throughout the experiment.
\end{abstract}

Index terms: Triticum aestivum, fumigation, germination, vigour.

\footnotetext{
${ }^{1}$ Submetido em $15 / 04 / 2006$. Aceito para publicação em 21/02/2007. Parte da Tese de Doutorado em Engenharia Agrícola, apresentada pelo primeiro autor à FEAGRI, UNICAMP.

${ }^{2}$ Eng $^{\circ} \mathrm{Agr}^{\circ}$, Doutor, Centro de Insumos Estratégicos e Serviços Especializados, Instituto Agronômico de Campinas, Caixa Postal 28, CEP
}

13001-970, Campinas (SP). 1rochajr@iac.sp.gov.br;

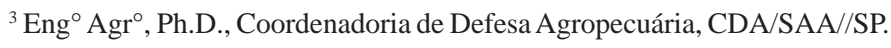
Prof. Credenciado da FEAGRI/UNICAMP. Caixa Postal 960, CEP 13073001, Campinas (SP). usberti@ cati.sp.gov.br. 


\section{INTRODUÇÃO}

A semente de trigo deve ser colhida tão logo complete a sua maturidade, pois permanecendo no campo pode ficar exposta ao risco de chuvas e ao ataque de pragas que, dessa maneira, se introduzem junto com o produto no armazém, causando grandes prejuízos à qualidade da semente.

As condições de clima quente e úmido em quase todo o território brasileiro também propiciam um ambiente ideal para o desenvolvimento de pragas e de doenças durante o armazenamento, tornando necessário adotar medidas efetivas de proteção e controle, visto que os prejuízos decorrentes atingem níveis elevados, com perdas ao redor de $20 \%$ (Gallo et al., 1978).

Segundo Hall (1971), nos países tropicais e subtropicais é comum a deterioração das sementes, manifestada pela perda de peso, por transformações químicas e pela presença de excrementos e fragmentos de insetos, que depreciam o produto comercialmente.

Para a conservação das sementes até a semeadura, a fosfina é o fumigante mais utilizado e difundido no expurgo durante o armazenamento. As principais pragas de armazenamento do trigo, Plodia interpunctella (Hueb., 1813), Rhyzopertha dominica (Fabr., 1792) e Sitophilus spp., são controladas com sucesso pela fosfina $\left(\mathrm{PH}_{3}\right) \mathrm{e}$, deste modo, a aplicação básica de $2 \mathrm{~g} \cdot \mathrm{m}^{-3}$ do produto é recomendada para um eficiente controle de ovos, larvas, pupas e adultos desses insetos. Portanto, o tempo de exposição a que são submetidos os insetos deve também objetivar a eliminação das formas jovens, que respiram com menor intensidade (ovos e pupas).

Estudando a ação da fosfina no controle de Sitophilus spp. em trigo, no interior de silos, Heseltine e Thompson (1959), verificaram que os estádios imaturos eram mais resistentes, necessitando elevar a dosagem do fumigante para o controle de pupas novas.

O expurgo ou fumigação, sendo o único tratamento curativo disponível, deve ser utilizado para a máxima eficiência. No entanto, as sementes recebem tratamentos preventivos, porém com dosagens e/ou períodos muitas vezes irregulares, ocorrendo com isto prejuízos em sua qualidade física e fisiológica.

A relação entre a umidade relativa e a temperatura do ambiente pode oferecer condições ótimas principalmente para a longevidade dos gorgulhos, pois é sabido que a maior infestação ocorre quando a temperatura está entre 26,6 e $29,4^{\circ} \mathrm{C}$ e o grau de umidade da semente acima de $12,5 \%$ (Fehn, 1970).

Elevadas temperaturas e umidades relativa do ar aceleram a reação da fosfina, enquanto que o ar seco e frio tem efeito contrário. No primeiro caso, a decomposição do produto pode completar-se em menos de 3 dias enquanto que. em temperaturas moderadas e baixa umidade. pode requerer 5 dias ou mais. A vedação ou isolamento do local a ser expurgado é o fator mais importante, pois não só assegura o controle total e eficiente de todas as fases do ciclo biológico dos insetos, como também protege as pessoas e todos os seres vivos nas vizinhanças do local (Bernardo, 1998).

O uso da fosfina no combate das pragas em grãos armazenados de acordo com Freire et al. (1968) foi altamente eficaz contra adultos do gorgulho dos cereais (Sitophilus oryzae), na dosagem de três pastilhas (3g de fosfina) por tonelada de grãos, durante 48 horas de exposição.

O objetivo deste experimento foi avaliar os efeitos físicos e fisiológicos em sementes de trigo, da aplicação de diferentes doses de fosfina, durante um período de 12 meses de armazenamento.

\section{MATERIALE MÉTODOS}

Foram utilizadas sementes de trigo das cultivares IAC24 e IAC-362, de ciclo médio, produzidas nos campos do Centro Experimental de Campinas (CEC), do Instituto Agronômico (IAC), da Secretaria de Agricultura e Abastecimento do Estado de São Paulo.

As sementes foram colhidas em julho de 2000 , secadas até $13 \%$ de grau de umidade, conforme os padrões de sementes adotados para comercialização no Estado de São Paulo (São Paulo, 2001), beneficiadas em agosto de 2000 no Centro de Produção de Material Propagativo do IAC e submetidas aos seguintes testes para a caracterização de sua qualidade física e fisiológica: a) pureza física, b) sementes infestadas, c) grau de umidade, d) peso hectolítrico, e) germinação e f) envelhecimento acelerado.

Pureza física: a amostra de trabalho de cada cultivar foi separada em sementes puras, outras sementes e material inerte. As sementes puras e o material inerte foram expressos em porcentagem por peso e as outras sementes em número por peso da amostra de trabalho, conforme recomendações das Regras para Análise de Sementes (Brasil, 1992).

Grau de umidade das sementes: foi determinado em três subamostras de sementes de cada cultivar, pelo método de estufa a $105 \pm 3^{\circ} \mathrm{C}$ durante 24 horas e expresso em porcentagem (Brasil, 1992).

Sementes infestadas: foi determinada a porcentagem de sementes danificadas por insetos, usando-se três subamostras de 50 sementes de cada cultivar, através de 
cortes individuais; para facilitar a execução dos cortes, as sementes foram previamente imersas em água pelo período de 24 horas (Brasil, 1992).

Peso hectolítrico: foram usadas duas subamostras por cultivar e uma balança específica, com capacidade de um litro de sementes, sendo o resultado expresso em kg.hl-1 (Brasil, 1992).

Germinação: foi conduzido a $20^{\circ} \mathrm{C}$ com quatro subamostras de 50 sementes por cultivar, semeadas em rolos de papel toalha Germitest, embebidos com volume de água equivalente a 2,5 vezes o peso do substrato. As porcentagens de plântulas normais foram determinadas em duas contagens, no quarto e no oitavo dia após a semeadura (Brasil, 1992).

Envelhecimento acelerado: foi realizado com quatro subamostras de 50 sementes por cultivar, colocadas em caixas plásticas (gerbox) com compartimento individual (mini câmaras), possuindo no seu interior uma bandeja de tela de aço inoxidável, onde foram distribuídas as sementes. No interior dessas mini câmaras foram adicionados $40 \mathrm{~mL}$ de água e as caixas plásticas foram mantidos a $42^{\circ} \mathrm{C}$, durante 60 horas (Aosa, 1983). Depois de retiradas da câmara de envelhecimento, as subamostras foram colocadas para germinar, de acordo com Brasil (1992).

A caracterização da qualidade física e fisiológica das sementes empregada, realizada logo após o beneficiamento, encontra-se no Tabela 1.

As sementes foram homogeneizadas, embaladas em sacos de algodão ( $\pm 8 \mathrm{~kg}$ de sementes cada), colocadas em prateleiras individuais e expurgadas com fosfina, no início e após 3, 6, 9 e 12 meses de armazenamento. O expurgo foi realizado dentro de tambores de 200 litros perfeitamente vedados, empregando-se comprimidos de $0,6 \mathrm{~g}$ nas doses em estudo, durante 120 horas.

Foram estabelecidos os seguintes tratamentos com fosfina nas sementes das cultivares IAC-24 e IAC-362: controle, sem aplicação de fosfina $\left(\mathrm{PH}_{3}\right)$; dose 1, com aplicação

TABELA 1. Características das sementes das cultivares de trigo IAC-24 e IAC-362, logo após o beneficiamento.

\begin{tabular}{lrr}
\hline \multirow{2}{*}{ Variáveis de qualidade } & \multicolumn{2}{c}{ Cultivares } \\
\cline { 2 - 3 } & IAC 24 & IAC 363 \\
\hline Pureza física (\%) & 99,90 & 99,97 \\
Grau de umidade (\%) & 11,61 & 13,50 \\
Sementes infestadas (\%) $^{*} 0,00$ & 0,00 \\
Peso hectolítrico (kg.hl $\left.{ }^{-1}\right)$ & 79,11 & 76,47 \\
Germinação (\%) & 92,5 & 96,5 \\
Vigor (envelhecimento acelerado) (\%) & 84,0 & 88,5 \\
\hline
\end{tabular}

de $1 \mathrm{~g} \cdot \mathrm{m}^{-3}$ de fosfina; dose 2 , com aplicação de $2 \mathrm{~g} \cdot \mathrm{m}^{-3}$ de fosfina; dose 4 , com aplicação de $4 \mathrm{~g} / \mathrm{m}^{3}$ de fosfina e dose 8 , com aplicação de $8 \mathrm{~g} \cdot \mathrm{m}^{-3}$ de fosfina.

O tratamento controle ficou isolado para proteção dos demais, sendo todos armazenados em condições de ambiente não controlado, no armazém do Centro de Produção de Material Propagativo (IAC).

Após a realização do primeiro expurgo e com as parcelas devidamente embaladas, iniciou-se o armazenamento em setembro de 2000, sendo que durante 12 meses as sementes permaneceram em prateleiras no mesmo ambiente, mas separadas em lotes, onde receberam as respectivas dosagens do produto.

No início e a cada três meses de armazenamento foram retiradas amostras das parcelas para avaliação dos parâmetros de qualidade, por meio dos testes de sementes infestadas, grau de umidade, peso hectolítrico, germinação e envelhecimento acelerado.

O delineamento estatístico empregado foi o inteiramente casualizado, em esquema fatorial com parcela subdividida no tempo, com os seguintes fatores: cultivares (2), dosagens de fosfina (5), com três repetições, e a comparação entre as médias foi realizada pelo teste de Tukey ao nível de $5 \%$ de probabilidade, para cada período de armazenagem. As porcentagens de germinação e de vigor foram previamente transformadas em arco seno $\sqrt{\% / 100}$ (Snedecor, 1945) enquanto que as porcentagens de infestação das sementes em $\sqrt{x+1}$, devido à ocorrência de muitos valores zero. Para as análises estatísticas foi empregado o programa SANEST (Zonta e Machado, 1986).

\section{RESULTADOS E DISCUSSÃO}

Não foram observadas interações significativas entre dosagens de fosfina e cultivares de trigo durante todo o experimento. A análise individual e a discussão dos resultados obtidos para cada parâmetro testado são apresentadas a seguir.

\section{Grau de umidade}

Na Tabela 2, observam-se diferenças nos valores iniciais de grau de umidade nas sementes entre as cultivares e que, a partir de 3 meses de armazenamento, os teores de água foram gradativamente entrando em equilíbrio com a umidade relativa do ar, até atingirem valores iguais aos 12 meses. Observa-se também que, após 6 meses de armazenamento, os graus de umidade para o tratamento controle foram superiores aos demais tratamentos devido ao crescente ataque do gorgulho 
TABELA 2. Graus de umidade de sementes de trigo, obtidos após a aplicação de fosfina durante armazenamento em condições ambientais de armazém.

\begin{tabular}{|c|c|c|c|c|c|}
\hline \multirow{3}{*}{ Cultivar } & \multicolumn{5}{|c|}{ Período de armazenagem (meses) } \\
\hline & 0 & 3 & 6 & 9 & 12 \\
\hline & \multicolumn{5}{|c|}{ Grau de umidade $(\%)$} \\
\hline IAC-24 & $11,76 \mathrm{~b}$ & $12,10 \mathrm{~b}$ & $12,08 \mathrm{~b}$ & $12,92 \mathrm{~b}$ & $12,00 \mathrm{a}$ \\
\hline IAC-362 & $13,19 \mathrm{a}$ & $12,61 \mathrm{a}$ & $12,56 \mathrm{a}$ & $13,35 \mathrm{a}$ & $12,08 \mathrm{a}$ \\
\hline \multicolumn{6}{|l|}{$\begin{array}{l}\text { Dose de } \\
\text { fosfina }\end{array}$} \\
\hline Controle & $12,56 \mathrm{a}$ & $12,12 \mathrm{~b}$ & $12,45 \mathrm{a}$ & $14,00 \mathrm{a}$ & $13,17 \mathrm{a}$ \\
\hline Dose 1 & $12,44 \mathrm{a}$ & $12,50 \mathrm{a}$ & $12,35 \mathrm{ab}$ & $12,94 \mathrm{~b}$ & $11,80 \mathrm{~b}$ \\
\hline Dose 2 & $12,45 \mathrm{a}$ & $12,45 \mathrm{a}$ & $12,38 \mathrm{ab}$ & $13,07 \mathrm{~b}$ & $11,84 \mathrm{~b}$ \\
\hline Dose 4 & $12,49 \mathrm{a}$ & $12,38 \mathrm{a}$ & $12,25 \mathrm{bc}$ & $12,82 \mathrm{~b}$ & $11,78 \mathrm{~b}$ \\
\hline Dose 8 & $12,40 \mathrm{a}$ & $12,32 \mathrm{ab}$ & $12,15 \mathrm{c}$ & $12,87 \mathrm{~b}$ & $11,66 \mathrm{~b}$ \\
\hline C.V. (\%) & 0,5 & 0,6 & 0,4 & 0,9 & 0,7 \\
\hline
\end{tabular}

Médias seguidas por letras iguais na coluna, não diferem entre si pelo teste de Tukey a $5 \%$ de probabilidade. C.V. = Coeficiente de variação.

(Sitophilus spp.). O equilíbrio higroscópico entre o ar e a semente é relevante durante o armazenamento, pois umidades relativas e temperaturas baixas são fatores limitantes para a sobrevivência e reprodução de muitos insetos.

As alterações no equilíbrio higroscópico de sementes são devidas ao rompimento da impermeabilização do pericarpo, já que os orifícios perfurados pelos insetos expõem o endosperma ao contato com o vapor de água do ar (Hall, 1971). O grau de umidade crítico para a reprodução dos insetos é de aproximadamente 9\%, porém isto é dificilmente alcançado pelo equilíbrio higroscópico em ambiente não controlado. À medida que a umidade da semente aumenta, entre 12 e $15 \%$, os insetos se desenvolvem e reproduzem com maior intensidade (Faroni, 1992).

Sementes infestadas

$\mathrm{O}$ ataque das pragas às sementes teve início após 3 meses de armazenamento, com mais intensidade no tratamento controle até o final do experimento (Tabela 3). Além disso, ocorreram diferenças entre as cultivares aos 6 e 9 meses de armazenamento, com uma preferência das pragas pelas sementes da cultivar IAC-362, provavelmente devido às suas características intrínsecas e por apresentarem um grau de umidade inicial mais elevado, conferindo assim melhores condições para o desenvolvimento dos insetos. Não foram observadas diferenças entre as dosagens de fosfina, verificando-se bom controle das pragas durante todo o armazenamento.

Na proteção do milho em palha D' Antonino et al. (1978) observaram que houve necessidade de nova aplicação de fosfina apenas quatro meses após o primeiro expurgo. Não foi observado efeito do tempo de exposição, nem mesmo nas pequenas dosagens. Após a segunda aplicação de fosfina, quatro meses após, foi observado efeito do tempo de exposição, com diferenças apenas para o menor tempo (48 horas), que apresentou maior grau de infestação.

\section{Peso hectolítrico}

Foram observadas diferenças significativas entre as cultivares para os valores de peso hectolítrico durante todo o experimento, conforme Tabela 4. Os maiores valores foram obtidos para a cultivar IAC-24 por apresentar sementes menores que ocupam melhor o espaço disponível. A partir de 6 meses de armazenamento, o tratamento controle mostrou uma queda brusca nessa variável, devido ao intenso ataque das pragas (Tabela 3 ).

A aplicação de diferentes dosagens de fosfina não

TABELA 3. Porcentagens de sementes infestadas de trigo após a aplicação de fosfina, durante armazenamento em condições não controladas

\begin{tabular}{|c|c|c|c|c|c|}
\hline \multirow{3}{*}{ Cultivar } & \multicolumn{5}{|c|}{ Período de armazenagem (meses) } \\
\hline & 0 & 3 & 6 & 9 & 12 \\
\hline & \multicolumn{5}{|c|}{$\%$} \\
\hline IAC-24 & 0,00 & 0,00 & $0,32 \mathrm{~b}$ & $2,57 \mathrm{~b}$ & $8,69 \mathrm{a}$ \\
\hline IAC-362 & 0,00 & 0,00 & $2,06 \mathrm{a}$ & $7,60 \mathrm{a}$ & $10,22 \mathrm{a}$ \\
\hline \multicolumn{6}{|c|}{ Dose de fosfina } \\
\hline Controle & 0,00 & 0,00 & $8,49 \mathrm{a}$ & $59,05 \mathrm{a}$ & $92,41 \mathrm{a}$ \\
\hline Dose 1 & 0,00 & 0,00 & $0,00 \mathrm{~b}$ & $0,31 \mathrm{~b}$ & $0,73 \mathrm{~b}$ \\
\hline Dose 2 & 0,00 & 0,00 & $0,31 \mathrm{~b}$ & $0,48 \mathrm{~b}$ & $0,43 \mathrm{~b}$ \\
\hline Dose 4 & 0,00 & 0,00 & $0,00 \mathrm{~b}$ & $0,00 \mathrm{~b}$ & $0,44 \mathrm{~b}$ \\
\hline Dose 8 & 0,00 & 0,00 & $0,00 \mathrm{~b}$ & $0,00 \mathrm{~b}$ & $0,00 \mathrm{~b}$ \\
\hline C.V. $(\%)$ & & & 29,5 & 29,9 & 19,0 \\
\hline
\end{tabular}

Médias seguidas por letras iguais na coluna, não diferem entre si pelo teste de Tukey a $5 \%$ de probabilidade. C.V. = Coeficiente de variação.

TABELA 4. Pesos hectolítrico de sementes de trigo, determinados após a aplicação de fosfina, durante armazenamento em condições não controladas.

\begin{tabular}{lccccc}
\hline \multirow{1}{*}{ Cultivar } & \multicolumn{5}{c}{ Período de armazenagem (meses) } \\
& 0 & 3 & 6 & 9 & 12 \\
\cline { 2 - 6 } & $79,18 \mathrm{a}$ & $78,49 \mathrm{a}$ & $77,78 \mathrm{a}$ & $75,99 \mathrm{a}$ & $72,13 \mathrm{a}$ \\
& $76,52 \mathrm{~b}$ & $76,32 \mathrm{~b}$ & $75,09 \mathrm{~b}$ & $71,96 \mathrm{~b}$ & $70,49 \mathrm{~b}$ \\
\hline IAC-24 & $77,73 \mathrm{a}$ & $77,50 \mathrm{a}$ & $74,76 \mathrm{c}$ & $65,26 \mathrm{~b}$ & $50,95 \mathrm{~b}$ \\
IAC-362 & $77,84 \mathrm{a}$ & $77,33 \mathrm{a}$ & $76,34 \mathrm{~b}$ & $75,69 \mathrm{a}$ & $75,94 \mathrm{a}$ \\
\hline Dose de fosfina & $77,84 \mathrm{a}$ & $77,25 \mathrm{a}$ & $76,86 \mathrm{ab}$ & $76,15 \mathrm{a}$ & $76,37 \mathrm{a}$ \\
Controle & $77,91 \mathrm{a}$ & $77,45 \mathrm{a}$ & $77,03 \mathrm{ab}$ & $76,44 \mathrm{a}$ & $76,66 \mathrm{a}$ \\
Dose 1 & $77,93 \mathrm{a}$ & $77,48 \mathrm{a}$ & $77,20 \mathrm{a}$ & $76,33 \mathrm{a}$ & $76,65 \mathrm{a}$ \\
Dose 2 & 0,3 & 0,3 & 0,6 & 1,6 & 2,5 \\
Dose 4 &
\end{tabular}

Médias seguidas por letras iguais na coluna, não diferem entre si pelo teste de Tukey a $5 \%$ de probabilidade. C.V. $=$ Coeficiente de variação. 
conduziu a diferenças significativas no peso hectolítrico. $\mathrm{O}$ ataque de pragas no tratamento controle foi se acentuando mês a mês, diminuindo a massa das sementes e conseqüentemente acentuando a diferença observada entre o valor dessa variável para o tratamento controle em relação aos com fosfina. Pingale et al. (1954) verificaram reduções de 1,73 e 5,61\% na massa de sementes de trigo atacadas por Ephestia cautella, em 3 e 6 meses de infestação, respectivamente.

\section{Germinação}

Pelas Figuras 1 e 2 pode-se observar, no início do experimento, diferenças de germinação entre as cultivares, provavelmente causada pelas diferentes condições ambientais durante a produção em campos de multiplicação. A fosfina, mesmo em aplicações com doses elevadas no armazenamento, não apresentou ação fitotóxica às sementes de trigo e o poder germinativo não foi alterado, mesmo com graus de umidade elevados, o que está de acordo com Puzzi, 1986. Com o decorrer do armazenamento, a porcentagem de germinação nos tratamentos controle decresceu devido ao intenso ataque das pragas.

Quando o tegumento apresenta danos, a respiração das sementes aumenta, com uma perda do seu poder germinativo (Hall, 1971). Este fato é também citado por Howe (1952), que acrescentou que, mesmo quando os danos não estão

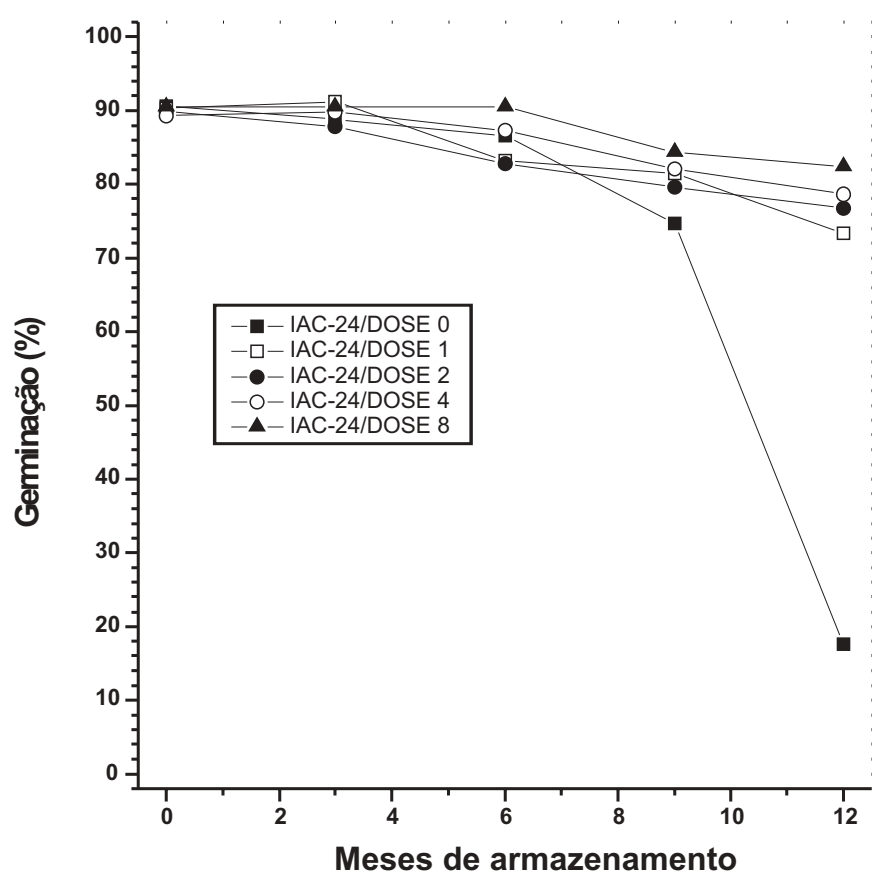

FIGURA 1. Porcentagens de germinação de sementes de trigo da cultivar IAC-24, obtidas após aplicação de doses de fosfina em armazenamento aberto.

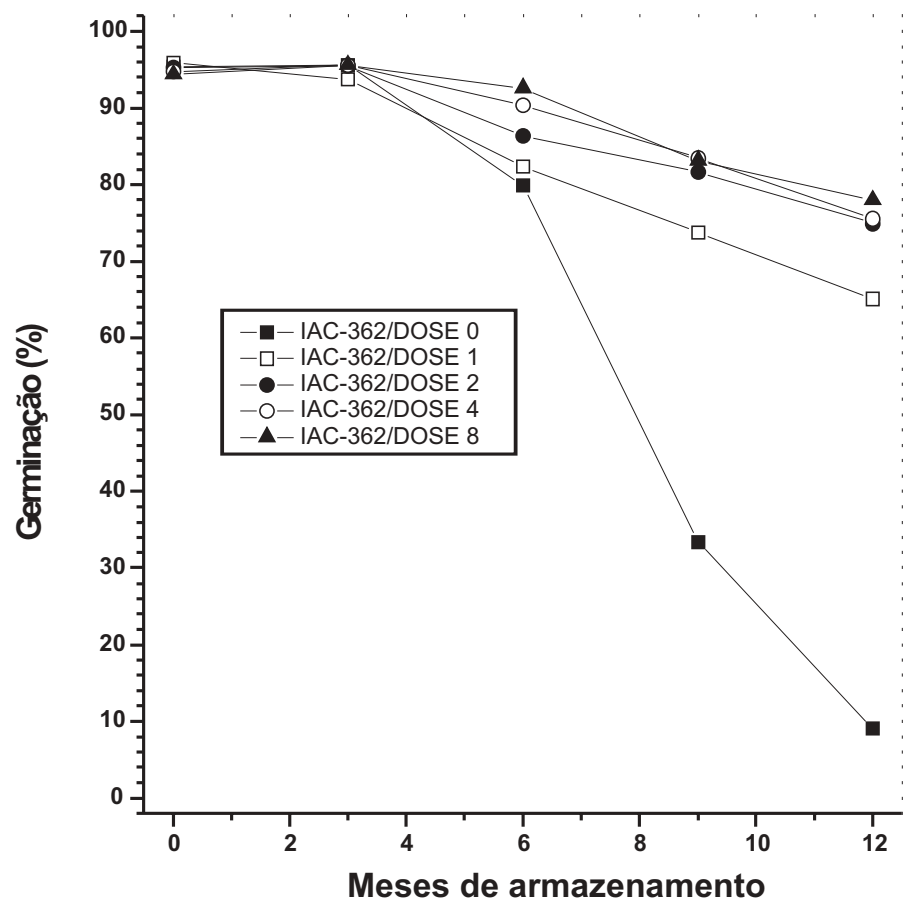

FIGURA 2. Porcentagens de germinação de sementes de trigo da cultivar IAC-362, obtidas após aplicação de doses de fosfina em armazenamento aberto.

aparentes, já existe uma perda de viabilidade das sementes, pois a redução do poder germinativo pode ser devida à destruição do embrião que, por ser mais mole, pode ser preferido pelos insetos.

A cultivar IAC-362 (Figura 2) apresentou os valores mais altos de porcentagem de germinação das sementes no tratamento controle até 6 meses de armazenamento, mas a partir daí houve inversão de posição, apresentando a cultivar IAC-24 os maiores valores nos meses finais (Figura 3), beneficiado pela preferência das pragas em atacar mais as sementes da IAC-362, provavelmente devido à sua diferente composição química. Estes resultados ficam mais evidentes através da Figura 3, que apresenta os valores médios de germinação das sementes das duas cultivares, durante o período de armazenamento. Com relação às dosagens de fosfina, observa-se através das Figuras 1 e 2 que os melhores resultados foram obtidos com 2,4 e $8 \mathrm{~g} \cdot \mathrm{m}^{-3}$, a partir de 6 meses de armazenamento; entretanto, com a dosagem de $1 \mathrm{~g} \cdot \mathrm{m}^{-3}$, que é a metade da dosagem recomendada, apenas a germinação das sementes da cultivar IAC-362 foi reduzida a partir de 9 meses de armazenamento.

\section{Vigor (envelhecimento acelerado)}

Houve uma redução generalizada e crescente nos valores 
de vigor durante o experimento, conforme se verifica pelas Figuras 4 e 5 para as sementes dos cultivares IAC-24 e IAC362, respectivamente. A cultivar IAC-362 apresentou os melhores valores, desde a origem do campo de produção (Tabela 1 e Figura 6). Com relação às dosagens de fosfina, os resultados obtidos foram semelhantes quanto a essa variável, em contraste com os valores de vigor mais baixos dos tratamentos controle a partir de 6 meses de armazenamento.

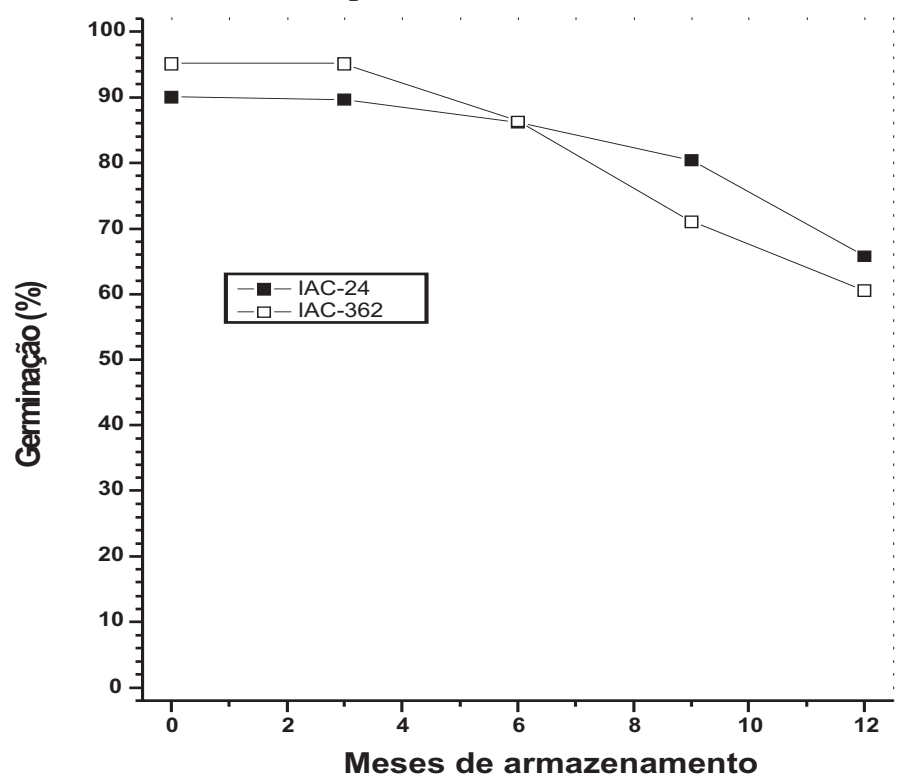

FIGURA 3. Porcentagens médias de germinação de sementes de trigo das cultivares IAC-24 e IAC-362, obtidas após aplicação de doses de fosfina e armazenamento aberto

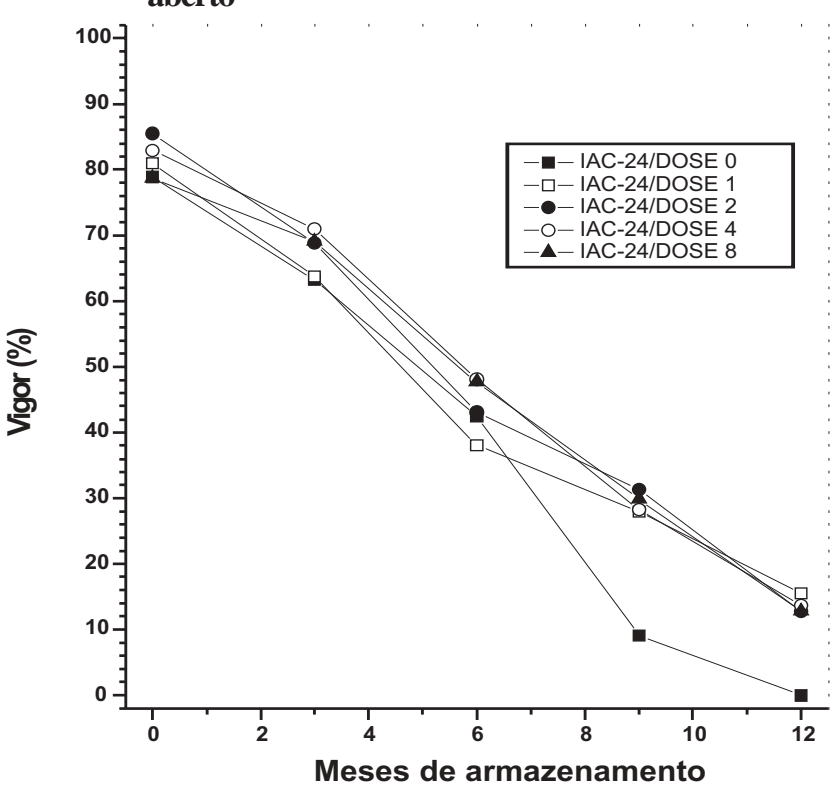

FIGURA 4. Porcentagens de vigor de sementes de trigo da cultivar IAC-24, obtidas após aplicação de doses de fosfina e armazenamento aberto.

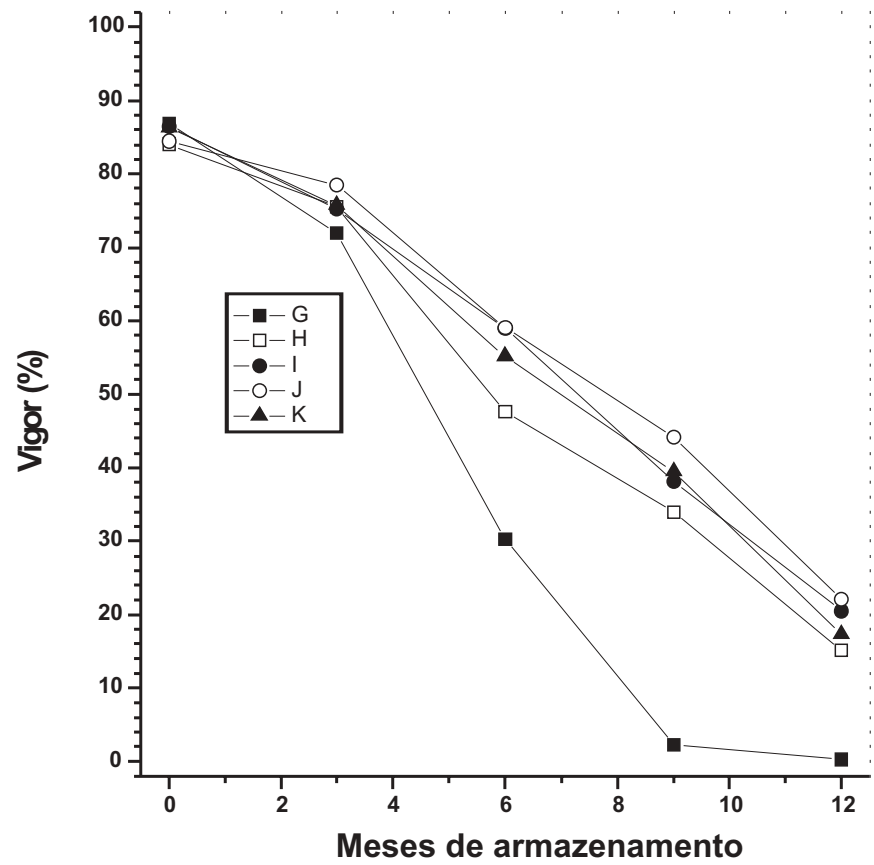

FIGURA 5. Porcentagens de vigor de sementes de trigo da cultivar IAC-362, obtidas após aplicação de doses de fosfina e armazenamento aberto.

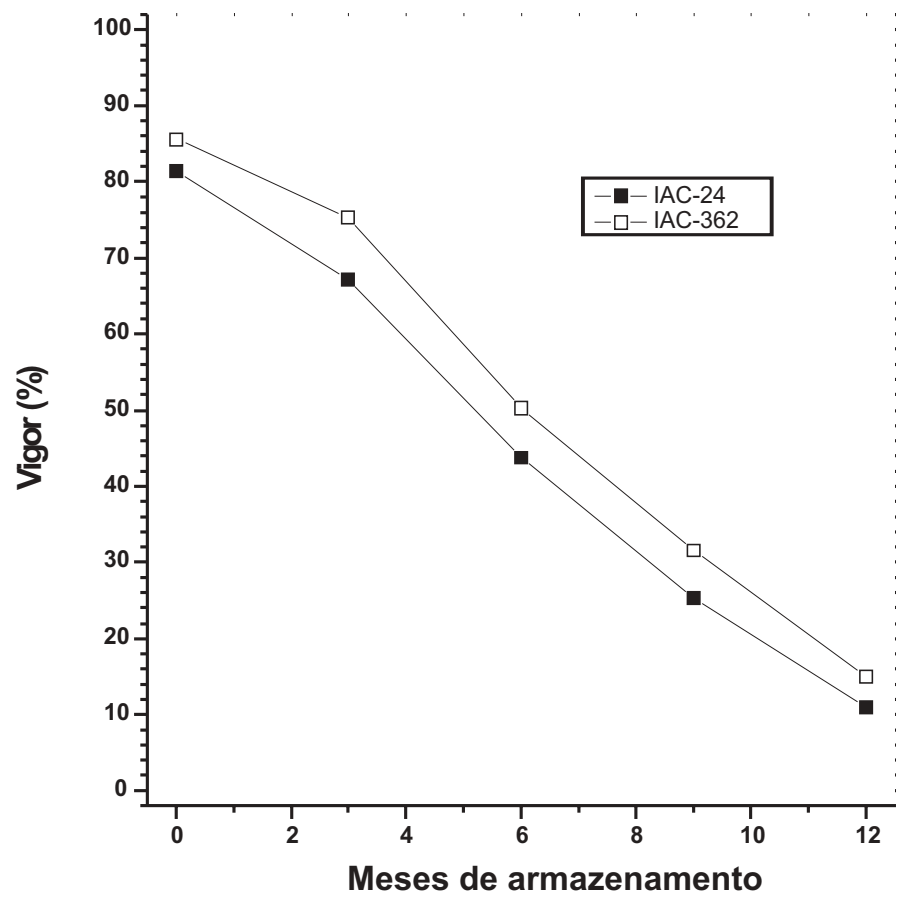

FIGURA 6. Porcentagens médias de vigor de sementes de trigo das cultivares IAC-24 e IAC-362, obtidas após aplicação de doses de fosfina e armazenamento aberto. 


\section{CONCLUSÕES}

Todas as dosagens de fosfina aplicadas em intervalos trimestrais e o período de exposição de 120 horas são eficientes no controle das pragas, resultando em níveis de infestação das sementes inferiores a $1 \%$ durante o armazenamento.

As sementes da cultivar IAC-362 são mais suscetíveis ao ataque de pragas durante o armazenamento do que as sementes de IAC-24.

A qualidade fisiológica das sementes não tratadas apresenta decréscimo mais acentuado que as sementes expurgadas a partir de seis meses de armazenamento

\section{REFERÊNCIAS}

ASSOCIATION OF OFFICIAL SEED ANALYSTS. Seed vigor test committee. Seed Vigor Testing Handbook. Lincoln, 1983. 88p. (Contribution, 32).

BRASIL. Ministério da Agricultura e Reforma Agrária. Regras para análise de sementes. Brasília: SNDA/DNDV/CLAV, 1992. 365 p.

D'ANTONINO, L.R.; DAN, E.L; DAN, E. Expurgo e proteção de milho em palha. Revista Brasileira de Armazenamento, Viçosa, v.3, n.4, p.39-45, 1978.

FARONI, L.R.D. Manejo das pragas dos grãos armazenados e sua influência na qualidade do produto final. Revista Brasileira de Armazenamento, Viçosa, v.17, n.1/2, p.36-43, 1992.

FEHN, L.M. Métodos de tratamento para conservação do trigo armazenado. Pesquisa Agropecuária Brasileira, Brasília, v.5, p.265-314, 1970.

FREIRE, J.A.M.; CIOCIOLA, A.I.; HARA, T. Uso de fosfina no combate das pragas em grãos armazenados. Boletim do Campo, v.31, p.20-8, 1968.

GALLO, D.; NAKANO, O.; SILVEIRA NETO, S.; CARVALHO, R.P.L.; BATISTA, G.C.; BERTI FILHO, E.; PARRA, J.R.; ZUCHI, R.A.; ALVES, S.B. Manual de Entomologia Agrícola. São Paulo: Agronômica Ceres, 1978. 531p.

HALL, D.W. Manipulación y almacenamiento de granos alimenticios en las zonas tropicales y subtropicales. Roma: FAO, 1971. 400p.

HESELTINE, H.K.; THOMPSON, R.H. The use of aluminium phosphide tablets for the fumigation of grain. Review of Applied Entomology, Série A, Farnham Royal, v.47, p.307-309, 1959.

HOWE, R.W. Miscellaneous experiments with grain weevils. Entomologist's Monthly Magazine, Londres, v.8, p.252-255, 1952.

PINGALE, S.V.; RAO, M.N.; SWAMINATHAM, M. Effect of insect infestation on stored grain. Studies on soft wheat. Journal Science Food Agriculture, Londres, v.5, n.1, p.51-54, 1954.

PUZZI, D. Abastecimento e Armazenagem de Grãos. Campinas: Instituto Campineiro de Ensino Agrícola, 1986. 592p.

SÃO PAULO. Secretaria de Agricultura e Abastecimento. Coordenaria de Assistência Técnica Integral. Departamento de Sementes, Mudas e Matrizes. Padrões de sementes básicas, certificadas e fiscalizadas. Campinas, 2001. 10p.

SNEDECOR, G.W. Métodos estatísticos. Lisboa: Ministério da Economia, 1945. 469p.

ZONTA, E.P.; MACHADO, A.A. Sistema de análise estatística para microcomputadores - SANEST. Pelotas: UFPel, Instituto de Física e Matemática, 1986. 150p. 